\title{
CIRUJANOS OCULISTAS EN LA GACETA DE MADRID (S. XVIII) (II)
}

\author{
LÓPEZ DE LETONA C ${ }^{1}$
}

En este segundo trabajo queremos referirnos a cuatro cirujanos oculistas: Ramón Sánchez Bulas, Toribio Merino, otro francés afincado en España: Lorenzo Lemaire, y también a una mujer Victoria de Felix.

Sánchez Bulas ejerció en la localidad toledana de Santaolaya. Nuetra fuente de información nos aporta noticias de varios casos tratados por él.

Un «encantis carcinomatoso» que resolvió con la extracción total del globo ocular, evitando así los graves dolores que padecía el paciente.

Posteriormente trató a un sacerdote que estaba ciego como resultado de una operación de cataratas en ambos ojos: «Las cicatrices cubrían enteramente las niñas», consiguió que las tales cicatrices «adelgazasen a beneficio del uso de un específico» que aplicó a su ojo izquierdo. Procedió del mismo modo en el otro ojo y así consiguió que el paciente recuperase vista suficiente para poder valerse por sí mismo.

También sanó a un niño portador de un «estafiloma verdadero de resultas de una fluxión caquéctica que le insultaba ambos ojos». Usó pare ello el «específico» citado anteriormente. Debe tratarse de algún remedio empírico acaso fabricado por el mismo cirujano

Toribio Merino fue cirujano en Valladolid (1793), vivía en la calle Orates (hoy Cánovas del Castillo) y fue «Académico con exercicio en la Academia de Cirugía establecida en dicha ciudad».

Debe referirse a una institución semejante a la Real Academia de Medicina que venía funcionando desde comienzos del siglo XVIII.

También se nos hace saber que nuestro cirujano operaba cataratas por los dos métodos al uso (extracción y reclinamiento) desplazándose incluso a los pueblos próximos, como Boecillo donde intervino a un religioso o Iscar, Quintanilla de Arriba e incluso Peñaranda de Bracamonte.
En Valladolid trató al sacristán de la cofradía de Jesus Nazareno, recordemos cómo esta institución, que existe al presente, fue una de las cuatro cofradías más importantes de la capital del Pisuerga.

En ocasiones las noticias de este personaje son repetitivas como en otras varias ocasiones.

Queremos indicar algo ahora del cirujano francés residente en España, Lorenzo Lemaire y de su discípula Victoria de Felix.

Del primero nos aparecen fechas concretas y pacientes tratados: El 12 de noviembre de 1776 operó al vecino de Madrid Domingo González de la consabida catarata por el procedimiento extractivo, «le acompañaron diversos cirujanos» «Y personas de calidad».

Evidentemente ya por entonces este tipo de intervenciones quirúrgicas tenían cierto componente espectacular.

En 1787 viene a Valladolid y se ofrece en el «Diario Pinciano» una noticia por la que sabemos de su estancia en esta ciudad, vivía en la calle Gallegos casa número 3, como en otras ocasiones conocemos nombres de enfermos, un eclesiástico, en este caso Mercedario Descalzo, que una vez operado «salió de su convento sin ayuda de persona ni báculo». Igualmente Doña Cleta Velasco.

Las personas que presenciaron las intervenciones «admiraron la limpieza, rapidez y caridad con que las ejecutó».

Incluso se comprometía a asistir gratis a los «pobres de solemnidad que se le presenten sin diferencia de sexo o de edad».

Más adelante nos enteramos de sus diversos domicilios madrileños entre 1795 y 1796, fueron de comienzo la calle de la Cruz, luego la del Espíritu Santo y finalmente la del Pez. Hay que recordar que las tres existen al presente.

Cerramos el presente trabajo con una curiosa referencia, se trata de una mujer: Victoria de Felix

\footnotetext{
1 IOBA. Valladolid. España.

E-mail: berta@ioba.med.uva.es
} 
que nos ha aparecido en diversas ocasiones en nuestra fuente de información, las noticias que disponemos abarcan desde 1793 a 1801.

En la primera anualidad tenía diecinueve años y ya operaba cataratas, así como pterigions y fístulas lagrimales. Resulta curioso que sus domicilios madrileños coincidan con los de Lorenzo Lemaire, se apunta así la posibilidad de que fuese su discípula o incluso cierto grado de parentesco.

El año 1796 se desplaza a Cartagena operando de cataratas al gobernador local y otras personas, entre ellas a D. Alfonso Alburquerque y a su suegra Doña Encarnación Pugmarín que tenía setenta y conco años.

Ese mismo año nuevo desplazamiento, esta vez a Cádiz, tambien sanó a una persona de calidad el regidor perpetuo y alguacil mayor D. Sebastián Perez.
La Gaceta recoge puntualmente la noticia apuntando: «Queda la Doña Victoria próxima a regresar a Madrid». Así prosiguen las curaciones hasta los comienzos del siglo XIX.

Se nos plantean varios interrrogantes ¿Quién era en realidad Victoria de Felix? ¿Dónde había aprendido su oficio? Tengamos en cuenta que en España eran los años del reinado de Carlos IV y que pese a la ya existente Revolución Francesa aquí se vivía en un estado de total ignorancia al respecto.

Por otro lado ¿Cuá era su relación exacta con Lorenzo lemaire?, se nos podría plantear la posibilidda de que ella fuese incluso francesa pero nuestra Gaceta no nos indica nada al respecto.

Pero todo ello nos da una pista curiosa, solo parangonable a la existencia dos siglos más tarde de Trinidad Arroyo. 